\title{
CARTOGRAFIA DO RELEVO: UM ESTUDO APLICADO NA REGIÃO OESTE DE MINAS GERAIS
}

\author{
Paula Cristina Almeida de Oliveira \\ Universidade Federal de Uberlândia, Laboratório de Geomorfologia e Erosão dos Solos \\ Av. João Naves de Ávila 2121, Sala 1H16, Santa Mônica, Uberlandia, MG \\ paulinhageo@yahoo.com.br
}

Sílvio Carlos Rodrigues

Prof. Dr. Universidade Federal de Uberlândia Avenida João Naves de Ávila, 2121, sala 1H16. CEP: 38.408-100. Uberlândia, MG silgel@ufu.br

\begin{abstract}
Resumo
A pesquisa geomorfológica tem como finalidade analisar as formas do relevo, buscando compreender os processos pretéritos e atuais, bem como os elementos de sua formação. Dessa forma, os mapeamentos temáticos se tornam essenciais para o planejamento físico-ambiental, já que a espacialização e localização dos fatos permitem representar e compreender as formas do relevo e a dinâmica dos processos. O objetivo deste trabalho é confeccionar o mapa geomorfológico da região de São Gonçalo do Abaeté, Varjão de Minas, Tiros e João Pinheiro, em Minas Gerais, identificando e definindo os diferentes padrões de organização do relevo. A região abordada por este estudo apresenta como Unidade Morfoestrutural da Bacia Sedimentar do São Francisco e abrange duas Unidades Morfoesculturais, o Planalto do São Francisco com Superfície Preservada e o Planalto do São Francisco com Superfície Rebaixada.
\end{abstract}

Palavras-chave: mapeamento geomorfológico, planejamento ambiental, Bacia do São Francisco.

\begin{abstract}
The geomorphologic research aims to analyze the landforms, looking for understand the past and actual processes, as well the elements that operates in its formation. In this way, the thematic maps become essential to the environmental planning, as the spatial location of the facts and allow represent and understand the forms of relief and dynamics of the processes. The objective of this paper is making the geomorphologic map of the region of São Gonçalo of Abaeté, Varjão of Mines, Tiros and João Pinheiro, in Minas Gerais, identifying and defining the different landform patterns. The region addressed by this study is located at the morpho-structure of São Francisco Sedimentary Basin and covers two morpho-sculptures, the San Francisco Preserved Plateau with flat surfaces and the dissected area located in the same plateau.
\end{abstract}

Keywords: geomorphologic map, environmental planning, San Francisco Basin.

\section{Introdução}

A pesquisa geomorfológica tem como finalidade analisar as formas do relevo, buscando compreender os processos pretéritos e atuais, bem como os elementos de sua formação.
As bases para pesquisa geomorfológica estão nas concepções de Penck (1953 apud Ross, 1992), que percebeu que as atuais formas do relevo da superfície terrestre são produtos da ação dos processos endógenos (abalos sísmicos, dobramentos fraturas, falhas, vulcanismo) e exógenos (fatores 
climáticos, processos erosivos), e também nas concepções de Guerasimov e Mercejakov (1968 apud Ross e Moroz, 1996), que desenvolveram os conceitos de morfoestrutura e morfoescultura.

Para esses autores, a morfoestrutura é gerada a partir de movimentos crustais, cujo produto gera formas de relevo controladas por estruturas, como por exemplo, as faixas dobradas, formas vulcânicas, áreas com blocos falhados, entre outras. As morfoesculturas seriam formas de relevo geradas, principalmente, a partir da atuação climática, que esculpe a superfície. Ainda para os referidos autores, não existe hierarquização de tamanho ou de gênese entre morfoesculturas e morfoestruturas, pois uma independe da outra para sua existência concreta. Outros autores, como Ross (1992), Brasil (1983) tratam de forma hierárquicas a relação morfoestrtura/morfoescultura. Para estes autores, as morfoesculturas são consideradas como áreas menores das morfoestruturas, que foram esculpidas através de processos exógenos específicos.

No Brasil, seguindo as contribuições alemã e soviética, destacam-se A. A. de Abreu, que apresenta o trabalho de análise morfológica do Planalto de Diamantina (Abreu, 1982) e J. L. S. Ross, que analisa a Província Serrana de Mato Grosso (Ross, 1987).

Segundo Ross (1992), na medida em que as formas do relevo expressam, através de seus componentes, a dinâmica das forças que plasmaram o veículo material que lhes dá existência nos permite avaliar as influências diretas da esculturação e o desenvolvimento subseqüente dos processos.

Desta forma, por exemplo, as características morfoestruturais de um cinturão orogenético influenciam a conformação do modelado da morfoescultura, bem como acabam por influenciar a tipologia de formas de relevo dominante e até mesmo nas formas individualizadas, como vertentes e microformas de relevo. Nos ambientes tropicais úmidos, o espessamento do manto de alteração e o processo de pedogênese tendem a camuflar as imposições estruturais, mas mesmo assim estas são identificáveis ao serem submetidas a investigações sistemáticas.

A proposição de Ross (1992), estabelecendo uma outra ordem taxonômica para o relevo terrestre, está calcada nessas considerações de natureza conceitual, ressaltando-se que o estrutural e o escultural estão presentes em qualquer tamanho de forma, e que suas categorias de tamanhos, idades, gêneses e formas são passíveis de serem identificadas e cartografadas separadamente e, portanto, em categorias distintas.

Ross (1992) apresenta uma proposta de classificação do relevo baseando-se no aspecto fisionômico das diferentes formas e tamanhos de relevo, tendo por base a gênese e a idade dessas formas.
Para Tricart (1965, apud Casseti 1994), o mapa geomorfológico representa uma melhor compreensão das relações espaciais e permite diversos tipos de tratamento, de acordo com o interesse da pesquisa.

Os mapeamentos temáticos são essenciais para o planejamento físico-ambiental, já que a localização dos fatos permite representar e tentar compreender as formas do relevo e a dinâmica dos processos. Os estudos geomorfológicos envolvendo o mapeamento assumem grande importância ao serem abordados no contexto geográfico, pois apresentam grandes contribuições no que tange ao planejamento e gestão territorial.

O objetivo deste trabalho é confeccionar o mapa geomorfológico da região oeste de Minas Gerais, abrangendo os municípios de São Gonçalo do Abaeté, Varjão de Minas, Tiros e João Pinheiro, identificando e definindo os diferentes padrões de organização do relevo. Neste sentido, buscou-se aplicar a metodologia de mapeamento geomorfológico proposta por Ross $(1992,1994)$ utilizando-se de ferramentas de cartografia assistida por computador.

\section{Condicionantes Regionais do Relevo}

As bases para o entendimento do relevo da região Oeste do Estado de Minas Gerais remontam ao período Cretáceo, no inicio da separação dos continentes africano e sulamericano. A partir deste momento o continente sul-americano passa por um período de calma tectônica e, portanto, os processos de geração de massas continentais são pouco expressivos, predominando os processos de denudação e formação de extensas superfícies de aplanamento e bacias de acumulação continental (Bigarella, 1971; Tomazzoli, 1990).

$\mathrm{O}$ ambiente variou, extremamente, entre períodos de extrema aridez e momentos de intensa umidificação, passando por um momento crítico de atividade vulcânica, que atingiu, em forma de derrames, as bacias sedimentares, tendo agido em locais específicos sob a forma de intrusões.

No período Terciário, por todo o território brasileiro desenvolveram-se, amplas superfícies de aplanamento, que podem ser encontradas atualmente, preservadas nos topos de serras e planaltos.

A orogenia andina foi outro processo de grande importância na evolução do relevo, visto que já se processava desde o Paleozóico, sendo acelerada no final do Mesozóico e durante todo o Cenozóico (Loczy \& Ladeira, 1980). A elevação desta cordilheira proporcionou reflexos em toda fachada leste do continente sul-americano, com um processo de epirogênese e soerguimento dos relevos serranos atuais e conseqüente reestruturação das bacias hidrográficas, e no caso das bacias sedimentares, a abertura de depressões periféricas ou interplanálticas. 
Como conseqüência da orogenia andina, ainda se destaca uma série de fossas tectônicas, como por exemplo, as fossas tectônicas que dão origem ao Pantanal e ao Complexo do Bananal.

As variações das características climáticas regionais são importantes para o entendimento da evolução do relevo, sendo que os efeitos diretos dos diferentes eventos glaciais de dimensão planetária não foram sentidos diretamente no continente sul-americano após o Terciário. No entanto, os efeitos das variações do nível do mar e seus reflexos sob os níveis de base regional e local interferiram na esculturação de novas superfícies de aplainamento, que compõem os níveis topográficos mais baixos de cada região. As mudanças no relevo pós-Pleistoceno possuem dimensões locais e abrangência regional, aparecendo nos perfis geométricos das vertentes, no aprofundamento dos canais de drenagem e formação de planícies e terraços fluviais.

As variações ambientais, em especial as condicionantes climáticas e a calma tectônica desempenharam papel importante no balanço morfo-pedogenético, com influência no desenvolvimento dos perfis de solo, bem como na geoquímica de superfície.

Durante o Pleistoceno, dois conjuntos de processos diferentes intercalaram-se, operando alternadamente e submeteram a paisagem a diversas variações. Em épocas glaciais e clima semi-árido, predominaram os processos de degradação lateral, enquanto nos períodos úmidos a dissecação fluvial predominou. A ação erosiva predominou nas fases de transição entre os dois períodos. Nas fases de transição todos os processos superficiais operantes alteraram seu funcionamento (Bigarella, 1971).

A configuração atual do ambiente na área de estudo é devida à instalação de um ambiente tropical com duas estações distintas. Os aspectos da compartimentação do relevo influenciam esta distribuição em dois níveis. Um primeiro nível é o regional, no qual a distribuição dos compartimentos de relevo conforma condições geográficas favoráveis ao desenvolvimento da vegetação de cerrado. Por outro lado, a característica individual de cada compartimento de relevo, como a distribuição e tipo material superficial, espessura do manto de intemperismo, densidade de drenagem, altitude e perfil geométrico das formas, acaba por interferir na tipologia vegetal e fito-fisionômica dos Cerrados.

\section{Área de estudo}

A região de estudo abrange os municípios de São Gonçalo do Abaeté, Varjão de Minas e João Pinheiro, integrantes da microrregião de Paracatu e o município de Tiros, que faz parte da microrregião de Patos de Minas, em Minas Gerais (Figura 1).
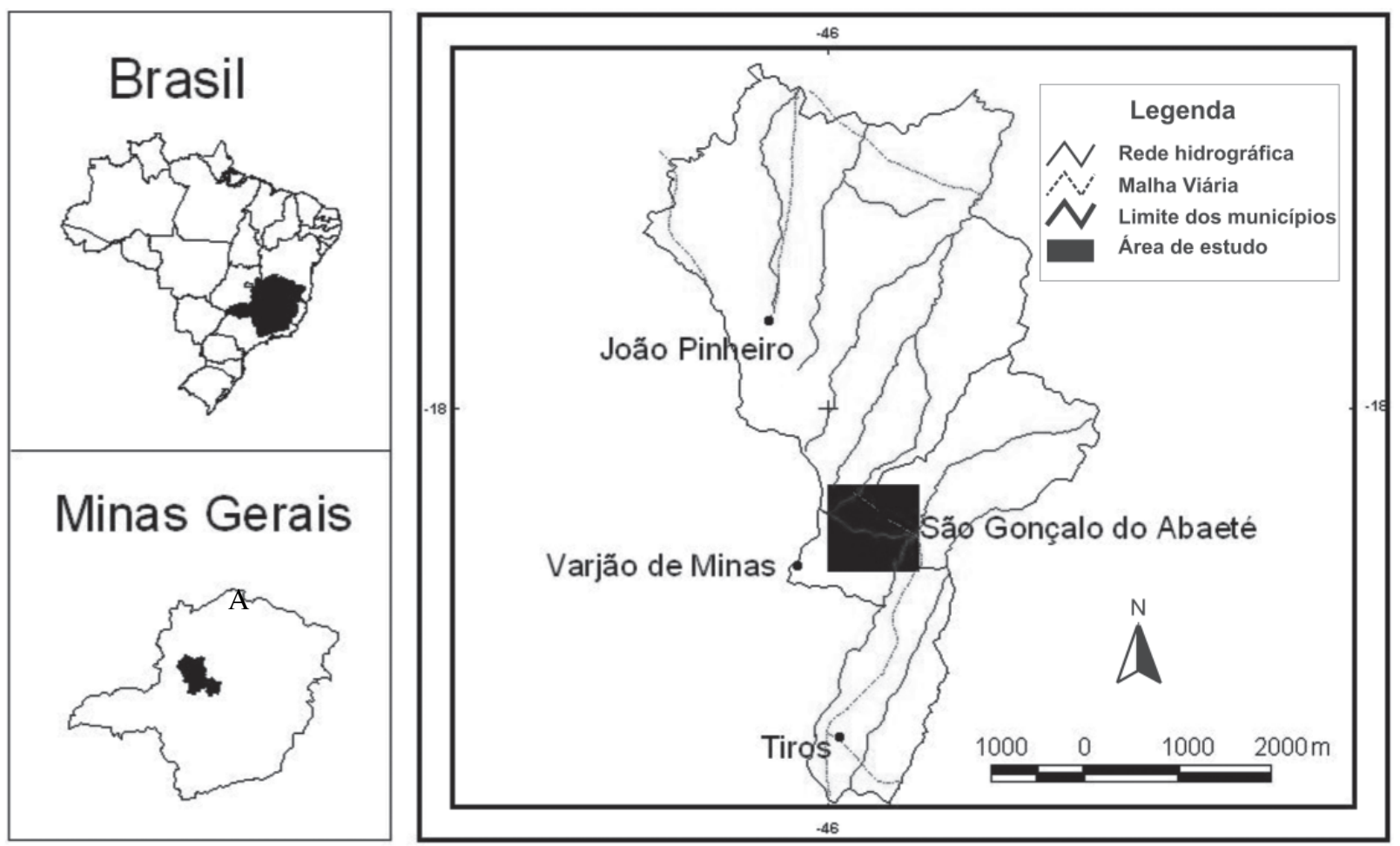

Figura 1 - Localização da área de estudo (Fonte:GEOMINAS, 2008). 
rede hidrográfica da região é composta principalmente pelos rios Borrachudo na região de Tiros, Rio, Abaeté e Córrego Santo Inácio na região de São Gonçalo do Abaeté e Varjão de Minas e pelos rios do Sono, Santo Antônio e Ribeirão das Almas na região de João Pinheiro. A rede hidrográfica está inserida na Bacia Hidrográfica do rio São Francisco. O clima da região é Tropical (Aw), a temperatura varia entre 22 e $23^{\circ} \mathrm{C}$ com chuvas predominantes no verão e invernos secos.

A região de estudo apresenta litologias fanerozóicas do Grupo Areado, Formação Mata da Corda e proterozóicas do Grupo Bambuí. O Grupo Areado é caracterizado por arenitos, siltitos e folhelhos, já a Formação Mata da Corda é representada por tufitos, lavas melanocráticas, arenitos cineríticos e lentes de arenito conglomeráticas. O Grupo Bambuí é representado por siltitos, arcósios filitos quartzitos, argilitos e folhelhos intercalados com calcário e dolomitos (Fundação CETEC, 1983; Campos \& Dardenne, 1997).

O relevo de Minas Gerais é caracterizado por planaltos, depressões e áreas dissecadas resultantes da atuação de processos morfoclimáticos, que foram extremamente favoráveis a elaboração de superfícies de aplainamento e ao aprofundamento dos cursos d'água.

A área de estudo está compreendida em uma única morfoestrutura correspondente a Bacia Sedimentar do São Francisco, correspondendo a afloramentos da Formação Mata de Corda e Grupo Areado. A morfoestrutura do Planalto do São Francisco apresenta neste trecho dois compartimentos morfoesculturais distintos, uma superfície preservada e outra dissecada. Uma delas é a unidade formada por superfícies tabulares (chapadas com coberturas sedimentares, predominantemente arenosas), delimitadas geralmente por rebordos erosivos bem marcados, recobertos por cerrado e veredas (Fundação CETEC, 1983). Por outro lado, as áreas dissecadas e deprimidas correspondem ao afloramento e compreendem o piso regional do relevo, que é afetado por rios que correm em direção ao São Francisco.

\section{Materiais e Métodos}

Primeiramente, foi realizado o levantamento bibliográfico sobre o mapeamento geomorfológico e sobre a área de estudo. Posteriormente, as imagens do projeto Shuttle Radar Topography Mission (SRTM) SE-23-Y-B-II-3-NO, SE-23-Y-BII-3-NE， SE-23-Y-B-II-3-SO， SE-23-Y-B-II-3-SE, disponibilizadas pela Embrapa (Miranda, 2005) na escala de 1:250.000, foram extraídas e georreferenciadas no software Autocad Map 2000. Após esse procedimento, foi realizada a montagem do mosaico com as imagens (Figura 2).

Em, seguida, tendo como base a imagem do mosaico, a rede de drenagem foi extraída, desenhando um layer específico, seguindo o traçado da drenagem. A mesma operação foi

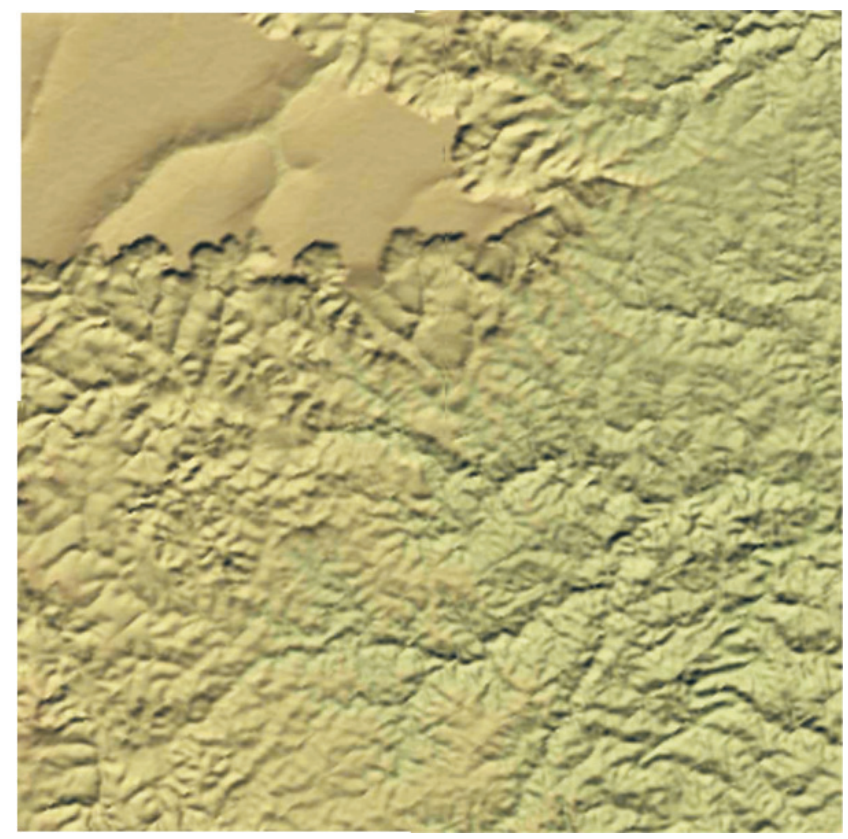

Figura 2 - Mosaico demonstrando os diferentes padrões de forma do relevo regional.

repetida para os padrões de forma semelhantes, por meio de interpretação visual das imagens.

Devido à escala de trabalho, foram considerados apenas quatro táxons. $\mathrm{O} 1^{\circ}$ táxon se refere às Unidades Morfoestruturais, ou seja, a identificação das formas de relevo mais antigas. O $2^{\circ}$ táxon se refere às Unidades Morfoesculturais, que são de dimensões inferiores às das Unidades Morfoestruturais, e com idade bem menor.

As Unidades Morfológicas ou Padrões de Formas Semelhantes representam o $3^{\circ}$ táxon, e retratam um determinado aspecto fisionômico decorrente das influências dos processos erosivos mais recentes e posteriores àqueles que esculpiram os planaltos e depressões. O $4^{\circ}$ táxon referese a cada uma das formas contidas no táxon anterior, ou seja, é o Tipo de formas de relevo (Figura 3).

A identificação dos Padrões de Formas Semelhantes é feita pela Matriz dos Índices de Dissecação do Relevo (Ross, 1992) adaptada dos trabalhos do Projeto Radambrasil (1983), onde se lê no primeiro digito (colunas verticais) o entalhamento dos vales e no segundo digito (colunas horizontais) a dimensão interfluvial media (Quadro 1).

As letras símbolo são de natureza agradacional (acumulação), recebendo a letra A, seguida do tipo de gênese, como por exemplo, a do tipo planície fluvial (pf) e veredas (v), e também de natureza denudacional (erosão). As formas denudacionais (D) são acompanhadas da informação do tipo de modelado dominante: aguçado (a), convexo (c), plano (p) e tabular (t). 


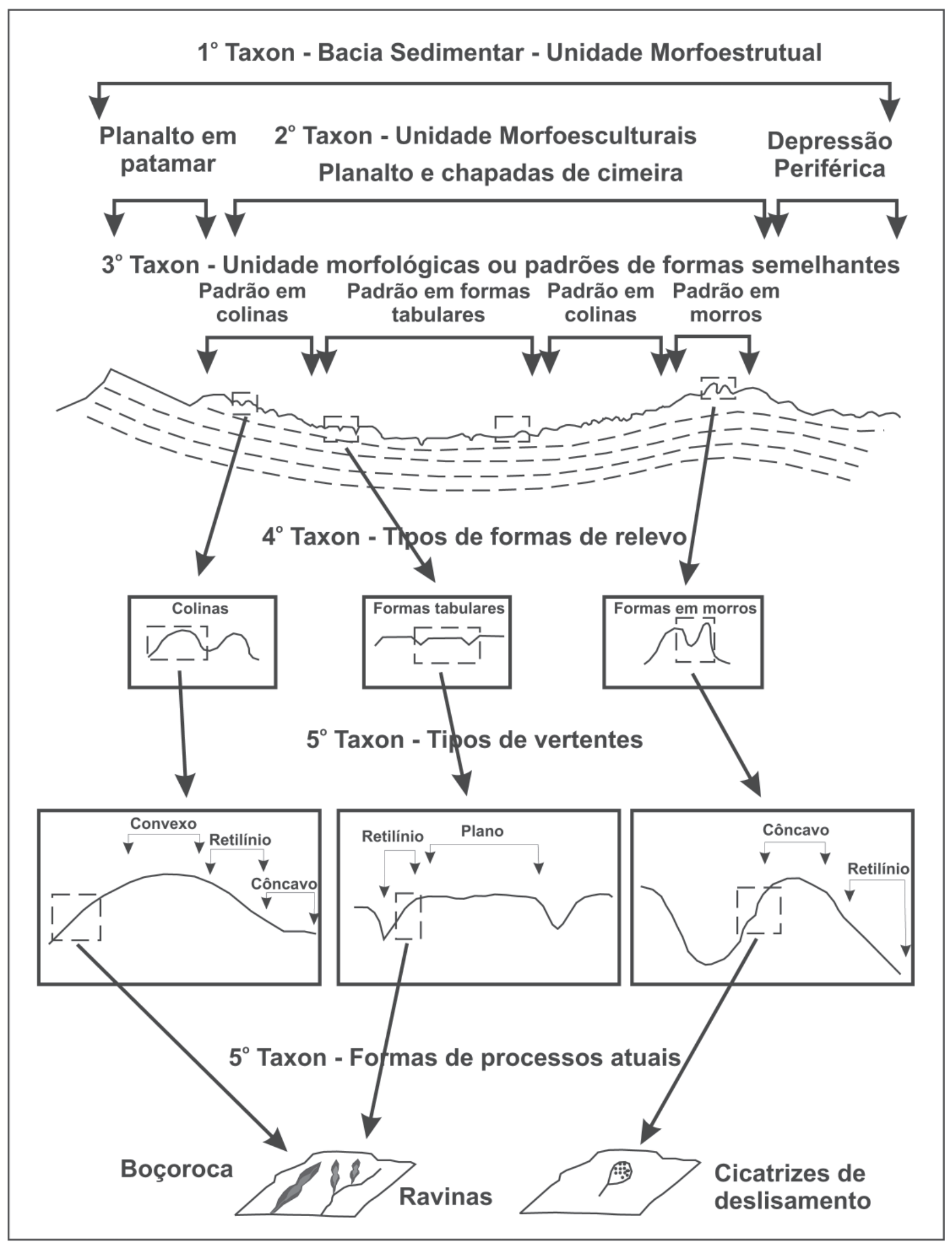

Figura 3 - Unidades Taxonômicas propostas por Ross (1992) 
Quadro 1: Matriz dos Índices de Dissecação do Relevo.

\begin{tabular}{|cccccc|}
\hline GRAU DE & \multicolumn{5}{c|}{ DIMENSÃO INTERFLUVIAL MÉDIA } \\
\cline { 2 - 6 } ENTALHAMENTO DOS & Muito Grande & Grande (2) & Média (3) & Pequena (4) & Muito Pequena (5) \\
VALES & $(1)>1500 \mathrm{~m}$ & 1500 a $700 \mathrm{~m}$ & 700 a 300m & 300 a $100 \mathrm{~m}$ & $<100 \mathrm{~m}$ \\
\hline Muito Fraco (1) $<10 \mathrm{~m}$ & 11 & 12 & 13 & 14 & 15 \\
Fraco (2) 10 a $20 \mathrm{~m}$ & 21 & 22 & 23 & 24 & 35 \\
Médio (3) 20 a $40 \mathrm{~m}$ & 31 & 32 & 33 & 44 & 45 \\
Forte (4) 40 a $80 \mathrm{~m}$ & 41 & 42 & 43 & 54 & 55 \\
Muito Forte (5) $>80 \mathrm{~m}$ & 51 & 52 & 53 & 54 \\
\hline
\end{tabular}

Fonte: ROSS (1992).

Os valores da dimensão interfluvial média foram encontrados através de medidas da distância entre os canais, realizadas no software Autocad Map 2000. Para o entalhamento dos canais de drenagem utilizou-se um padrão visual, visto que a área não dispõe de cartas topográficas.

A partir do Modelo Digital de Elevação (MDE) obtido do sensor SRTM foi possível a elaboração do mapa de hipsometria da área de estudo com o auxílio do software Arcview 3.2. As classes hipsométricas foram agrupadas em intervalos de 100 metros, gerando cinco classes: menor que 600m, 600 a $700 \mathrm{~m}, 700$ a $800 \mathrm{~m}, 800$ a 900m e maior que 900 metros.

\section{Resultados e Discussões}

A região abordada por este estudo apresenta como Unidade Morfoestrutural da Bacia Sedimentar do São Francisco e abrange duas Unidades Morfoesculturais, o Planalto do São Francisco com Superfície Preservada e o Planalto do São Francisco com Superfície Rebaixada (Figura 5).

No Planalto do São Francisco com Superfície Preservada foram identificados os seguintes padrões de organização do relevo:

- Av: corresponde a forma de acumulação (A) com presença de veredas $(\mathrm{v})$;

- Da 32: corresponde a forma denudacional aguçada com grau de entalhamento médio e dimensão interfluvial grande (1500 a 700 m). Essas áreas ocorrem próximas do rebordo erosivo, em altitudes de 800 a 900 metros;

- Dt 11: corresponde a forma denudacional tabular com grau de entalhamento muito fraco e dimensão interfluvial muito grande $(>1500 \mathrm{~m})$, que ocorrem no topo da chapada, com altitudes superiores a 900 metros.
No Planalto do São Francisco com Superfície Rebaixada as unidades morfológicas existentes se apresentam como:

- Dc 31 corresponde à forma denudacional côncava com grau de entalhamento médio e dimensão interfluvial muito grande $(>1500 \mathrm{~m})$. Apresenta colinas côncavas medianamente dissecadas. Ocorrem em diferentes níveis altimétricos, sendo o primeiro em altitudes que variam de 600 a 700 metros, e o segundo com níveis altimétricos variando de 800 a 900metros, com altitudes superiores a 900 metros no topo;

- Dc 42: corresponde a forma denudacional côncava com grau de entalhamento forte e dimensão interfluvial grande (1500 a $700 \mathrm{~m}$ ) ocorrendo em áreas com altitudes que variam de 800 a 900 metros;

- Da 44, que corresponde à forma denudacional aguçada com grau de entalhamento forte e dimensão interfluvial pequena (300 a $100 \mathrm{~m}$ ). Esse padrão de relevo ocorre próximo ao Rio Abaeté, me altitudes que variam de 600 a 800 metros.

A área mapeada é representativa das características regionais do relevo, pois indicam a existência de um conjunto de relevos escalonados, com uma superfície de cimeira representada por relevo residual em forma de chapada, considerado neste mapeamento como superfície preservada ao nível do $2^{\circ}$. táxon, e ao menos dois degraus inclinados em direção da drenagem regional, o Rio Abaeté, que abrange a superfície rebaixada. Esta configuração está de acordo com a organização da bacia hidrográfica maior, do Rio São Francisco, que orienta todos os esforços erosivos regionais.

Analisando-se o relevo da área pode-se observar que o mesmo guarda estreita relação com a configuração geológica. Com efeito, em se tratando de área de estrutura sedimentar homoclinal, é de se esperar a presença de ressaltos topográficos. Neste sentido, o posicionamento das áreas 


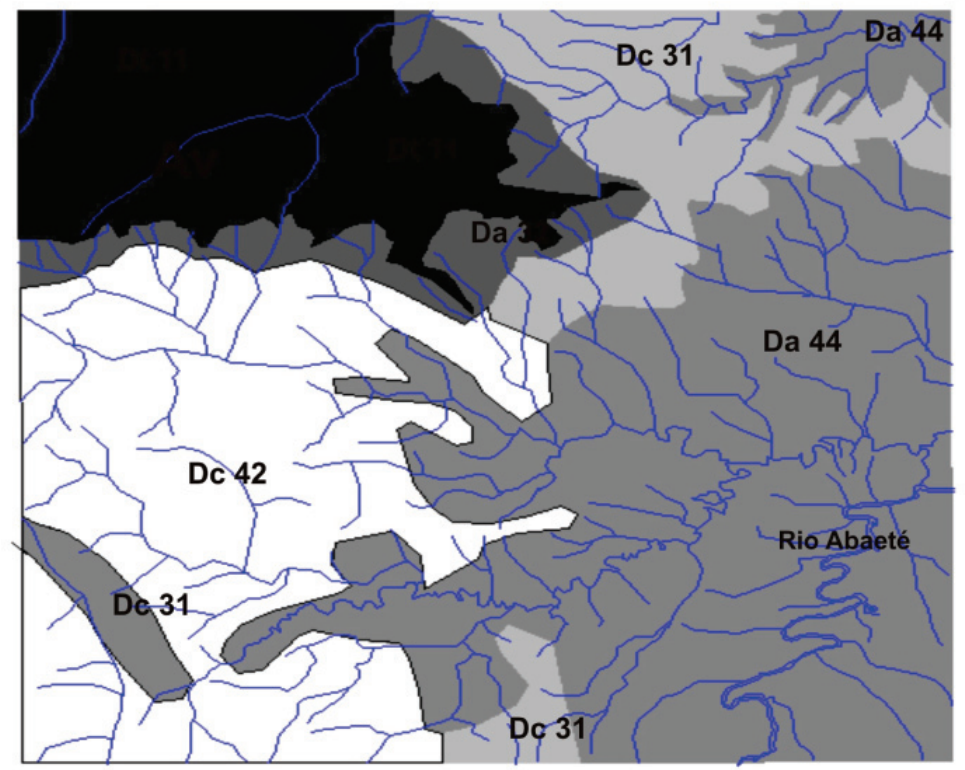

\begin{tabular}{|c|c|c|c|c|}
\hline $1^{\circ}$ TAXOII & $2^{\circ}$ TAXOII & $3^{\circ}$ TAXOII & \multirow{2}{*}{\multicolumn{2}{|c|}{$\begin{array}{l}\text { 4. TAXOII }^{\text {Formas de Relevo }} \\
\end{array}$}} \\
\hline Un. Morfoestrutural & Un. Morfoescutural & $\begin{array}{l}\text { Un. } \\
\text { Morfóógica }\end{array}$ & & \\
\hline $\begin{array}{l}\text { Badia Sedim entar do } \\
\text { Săo F randsco }\end{array}$ & $\begin{array}{l}\text { Planalto do Sắ } \\
\text { Francisco- Sup. } \\
\text { Presenvada }\end{array}$ & Dt & Dt11 & \\
\hline $\begin{array}{l}\text { Badia Sedim ertar do } \\
\text { Săo Frandisco }\end{array}$ & $\begin{array}{l}\text { Planalto do Săo } \\
\text { Francisco- }\end{array}$ & Av & Av & \\
\hline $\begin{array}{l}\text { Bada Sedim ertar do do } \\
\text { Săo Frandisco }\end{array}$ & $\begin{array}{l}\text { Planalto do Sáo } \\
\text { Francisco- }\end{array}$ & Da & Da 32 & \\
\hline $\begin{array}{l}\text { Badia Sedim entar do } \\
\text { Săo F randisco }\end{array}$ & $\begin{array}{l}\text { Planalto do Såo } \\
\text { Francisso- }\end{array}$ & DC & Dc 31 & \\
\hline $\begin{array}{l}\text { Badia Sedim ertar do } \\
\text { Sắo Frandisco }\end{array}$ & $\begin{array}{l}\text { Planalto do Sáo } \\
\text { Francisco- }\end{array}$ & DC & Do 31 & \\
\hline $\begin{array}{l}\text { Badia Sedim entar do } \\
\text { Săo F randisco }\end{array}$ & $\begin{array}{l}\text { Planalto do Sáa } \\
\text { Francisco- }\end{array}$ & DC & $D C 42$ & \\
\hline $\begin{array}{l}\text { Badia Sedim ertar do } \\
\text { Săo Frandisco }\end{array}$ & $\begin{array}{l}\text { Planalito do Sáá } \\
\text { Francisco- } \\
\text { Sup Rebaixada }\end{array}$ & $\mathrm{Da}$ & Da 44 & \\
\hline
\end{tabular}

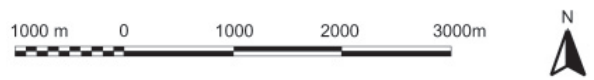

Figura 4-Mapa Geomorfológico da região de estudo (Fonte: imagens de satélite TM LANDSAT SE-23-Y-B-II-3-NO, SE-23-Y-B-II-3-NE, SE-23-Y-B-II-3-SO, SE-23-Y-B-II-3-SE - Escala 1:25.000).
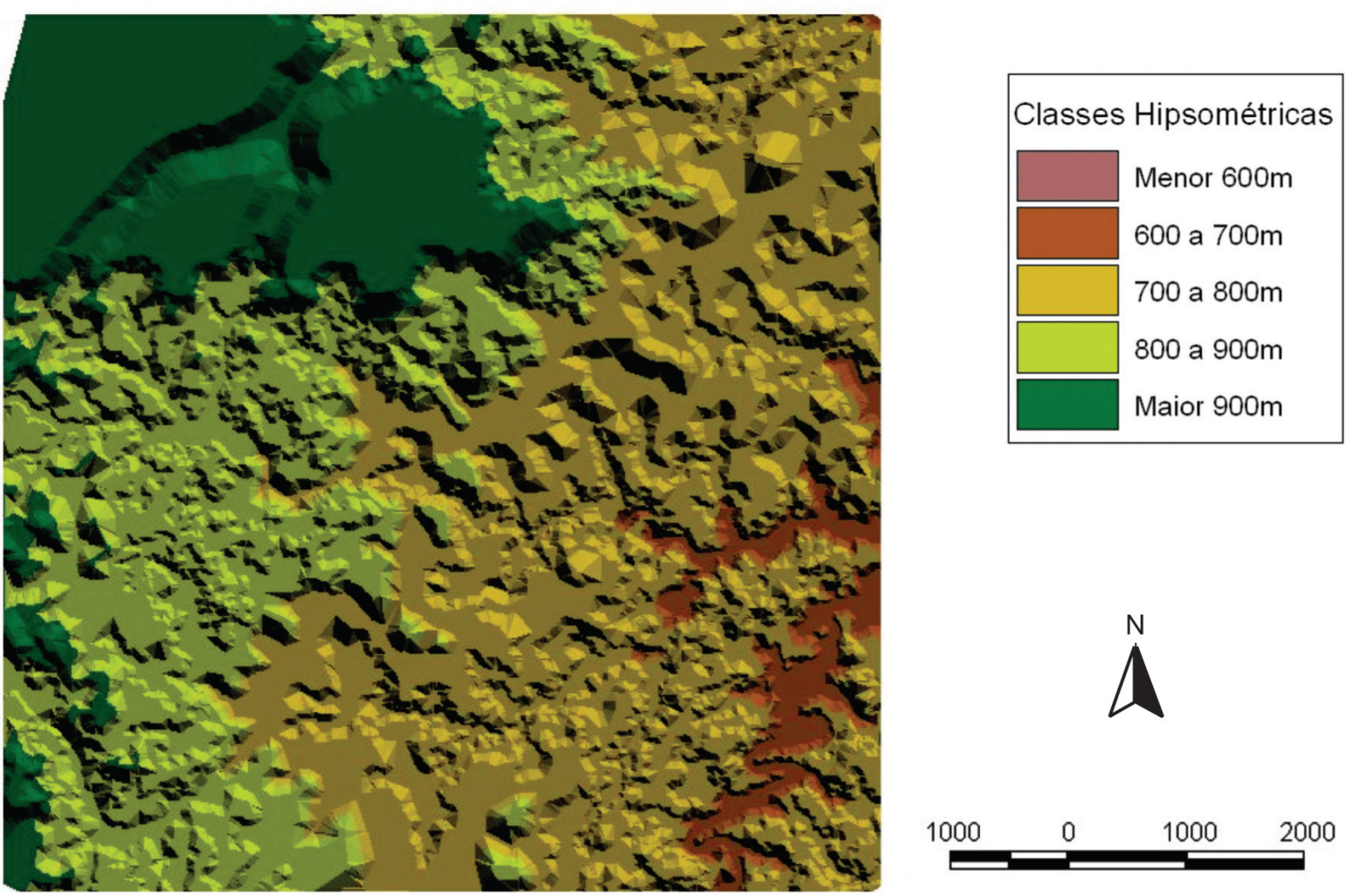

Figura 5 - Mapa Hipsométrico da região de estudo (Fonte: Miranda, 2005). 
preservadas de cimeira associado à presença de sedimentos cretácicos, indica que a área de estudo encontra-se em processo de esculturação por erosão a um longo tempo. Neste sentido a presença de bordas erosivas com forte grau de entalhamento é indicativa de que as diferentes litologias reagem distintamente ao processo de escultura, pois nesta área encontram-se também os contatos litológicos com as formações mais antigas (Figura 5).

\section{Conclusões}

As medições, tanto do grau de entalhamento, como da dimensão interfluvial dos vales, fornecem dados bem perceptíveis característicos de cada tipo de relevo. Nesse sentido, o mapa hipsométrico contribuiu para o entendimento das diferenças morfológicas e das formas de relevo presentes na área de estudo.

A identificação das superfícies de aplanamento em posição de cimeira indica as áreas com maior potencialidade para aproveitamento agrícola em função das amplas superfícies mapeadas como Dt11, que apresentam facilidades para a mecanização agrícola e implementação das modernas tecnologias de irrigação e agricultura de precisão. Também contribui para isto a presença das áreas de veredas (Av), que se preservadas, podem suprir a demanda hídrica para cultivos irrigados nestas áreas. Já as áreas com maior dissecação localizadas nas bordas da superfície de cimeira (Da32), estão indicadas à preservação ambiental, pois apresentam uma maior quantidade de nascentes de canais de primeira ordem, bem como vertentes mais inclinadas e suscetíveis a processos erosivos mais intensos no caso de desmatamento generalizado.

Na superfície rebaixada do planalto ocorrem formas com média a forte dissecação, implicando em condições de relevo onde predominam declividades médias superiores a 10\%, como os padrões de topo convexo, classificado como Dc31, e também muitos setores de vertentes que possuem declividades elevadas, como as que ocorrem nos padrões de forma com topo aguçado ou convexo e com forte entalhamento, classificadas como Dc42 e Da44, nos quais os usos da terra devem ser planejados de maneira a evitar a aceleração de processos erosivos naturais.

A identificação dos diferentes padrões de organização do relevo através do mapa geomorfológico assume grande importância, pois permite identificar áreas que são naturalmente vulneráveis a ação antrópica. Dessa forma, esse trabalho também atua como instrumento para o planejamento ambiental, fornecendo a administração pública municipal e à sociedade em geral um importante documento de compreensão da geomorfologia local.

De acordo com as categorias morfométricas estabelecidas por Ross (1994) que se referem à classificação dos relevos em função de sua potencialidade ambiental, a área de estudo apresenta com classes instabilidade potencial muito fraca (11), média $(31,32)$ e forte $(42,44)$.

\section{Referências}

Bigarella, J.J. (1971) Variações climáticas no Quaternário superior do Brasil e sua datação radiométrica pelo método de carbono 14. Paleoclimas, 1: 22p.

Brasil. Ministério das Minas e Energia. Projeto Radambrasil. (1983) Folha SE. 22 Goiânia: geologia, geomorfologia, pedologia, vegetação, uso potencial da terra. Rio de Janeiro, $764 \mathrm{p}$. (Levantamento de Recursos Naturais, 31).

Campos, J.E.G. \& Dardenne, M.A. (1997) Estratigrafia e Sedimentação da Bacia Sanfranciscana: Uma Revisão. Revista Brasileira de Geociências, 27(3): 269-282.

Casseti, V. (1994) Elementos de Geomorfologia. Goiânia: Editora da UFG. $137 \mathrm{p}$.

Fundação Centro Tecnológico de Minas Gerais / CETEC. (1983) Diagnóstico Ambiental do Estado de Minas Gerais. Belo Horizonte: CETEC (Série de Publicações Técnicas, 10). v. 1. 158 p.

Miranda, E. E. (2005) Brasil em Relevo. Campinas: Embrapa Monitoramento por Satélite. Disponível em: $<$ http:/ /www.relevobr.cnpm.embrapa.br>Acesso em: 10 nov. 2006

Loczy, L. \& Ladeira, E.A. (1980) Arcabouço Estrutural da América do Sul. In: Loczy, L. \& Ladeira, E.A. (Eds.). Geologia Estrutural e Introdução a Geotectônica. Rio de Janeiro: Ed. Edgard Blucher. p. 366-380.

Ross, J.L.S. (1922) O Registro Cartográfico dos Fatos Geomórficos e a Questão da Taxonomia do Relevo. Revista do Depto. de Geografia-FFLCH-USP, 6: 17-29.

Ross, J.L.S. (1994) Análise Empírica da Fragilidade dos Ambientes Naturais e Antropizados. Revista do Depto. de Geografia-FFLCH-USP, 8: 63-74.

Ross, J.L.S. \& Moroz, I.C. (1996) Mapa Geomorfológico do estado de São Paulo. Revista do Depto. de Geografia-FFLCH-USP, 10: 41-58.

Tomazzoli, E.R. (1990) A evolução geológica do Brasil-Central. Revista Sociedade e Natureza, 2 (3): 11-26. 